\title{
Depth Estimates of Large Earthquakes on the Island of Hawaii Since 1940
}

\author{
Holly K. EISSLeR and Hiroo Kanamori
}

Seismological Laboratory, California Institute of Technology

\begin{abstract}
Although hypocenters of earthquakes on the island of Hawaii are now routinely assigned to within $5 \mathrm{~km}$, depth was a poorly determined parameter until the early 1960 's. However, the 19501960 period was very active both in volcanic eruptions and large earthquakes. Source depths for the 12 largest Hawaiian earthquakes (magnitude 6 or greater) since 1940 are estimated from the ratios of body and surface wave amplitudes recorded at Pasadena, California. Excitation functions for Rayleigh waves are calculated as a function of source depth for the two dominant periods in the Pasadena records, $8 \mathrm{~s}$ and $20 \mathrm{~s}$. Theoretical body wave amplitudes are determined from synthetic seismograms. Calculated ratios are very sensitive to source depth; for example, amplitudes of 8-s Rayleigh waves diminish by a factor of 300 between depths of $10 \mathrm{~km}$ and $50 \mathrm{~km}$. This is a much larger effect than the fault geometry, which we estimate to be a factor of 4 between representative focal mechanisms. Estimated depths for post-1960 earthquakes agree fairly weil with the instrumental depths. In general, large earthquakes near the volcanic flanks and fault systems are shallow $(\leqslant 20 \mathrm{~km})$. Two earthquakes of magnitude 6 occurred under the volcanoes Mauna Loa (in 1950) and Kilauea (in 1951); they preceded major eruptions by 3 days and 14 months, respectively, and had the largest depth estimates at 40-55 km and $35-50 \mathrm{~km} . M_{S}$ values assigned from global amplitudes are compared with those assigned from Pasadena amplitudes alone, for 70 events in $1973-1974$ with $5.1 \leqslant M_{S} \leqslant 6.0$. The global values are only slightly larger ( 0.05 magnitude units) than the Pasadena values, indicating that Pasadena amplitudes are on the average representative of the event magnitude.
\end{abstract}

\section{INTRODUCTION}

Several moderate to large earthquakes, magnitude 6 or greater, occurred on the island of Hawaii in the 1950's. Some of these were spatially and temporally associated with volcanic eruptions. Two events in 1950 and 1951 under the summits of Mauna Loa and Kilauea preceded eruptions of the volcanoes, the first by less than 1 week. Although the depths of these events were not well determined, there was some indication that the 1951 Kilauea earthquake was deep, about 40 or $50 \mathrm{~km}$. In general, the larger earthquakes in Hawaii are much shallower, $<20 \mathrm{~km}$, and they are not necessarily associated with specific eruptions or volcanic centers.

The depth of an earthquake is significant because it may indicate how the seismic activity is associated with the volcanic process. For example, some of the deepest seismicity on Hawaii consists of intense swarms of small earthquakes at about $50-60 \mathrm{~km}$ beneath Kilauea. Deep swarms have long been thought to signify the movement of magma upward into the shallow reservoirs of the volcanic system. Small shallow earthquakes may also occur due to rock failure induced by increased magmatic pressure in the reservoirs. Many of the large shallow earthquakes are in response to regional tectonic stresses that arise from the building up of the large volcanic load on the old seafloor. Although all earthquakes in Hawaii are connected in some way to its

\footnotetext{
Copyright 1986 by the American Geophysical Union.
}

Paper number 4B5311

0148-0227/86/004B-5311\$05.00 volcanism, some events appear to have a more primary relationship to the volcanic process than others.

Modern array coverage on Hawaii began to develop in 1955-1960. Hypocenters assigned after 1960 are quite reliable for the larger earthquakes. Before this, depths were esimated primarily from noninstrumental information, such as isoseismal patterns. Here, we use a simple technique to arrive at another estimate of depth or, at least, relative depth ranking, for the largest earthquakes in Hawaii since 1940.

Seismic instruments in Pasadena, California, have been continuously recording for over 50 years. Prior to worldwide standardization of equipment in 1963, these instruments were among the highest gain in operation. Pasadena was also one of the closest stations to Hawaii and thus could record its intermediate-magnitude events. Events of magnitude 6 were clearly recorded on both long- and shortperiod Pasadena instruments, and the relative amplitudes of surface and body waves can be compared in the two different period bands. While the excitation of Rayleigh waves decreases rapidly with source depth, body wave amplitudes are a much weaker function of depth. By comparing calcuations of the relative excitation of these waves as a function of source depth to the Pasadena data set, estimates of the depths of the events can be obtained.

\section{EARTHQuake Data}

Seismicity on the island of Hawaii is illustrated by Figure $1 a$, which shows all earthquakes greater than magnitude 3.5 since 1970 in the NOAA catalog. Locations of the volcanic centers and major fault zones are shown in Figure $1 b$. The Hilina, Kealakekua, and Kaoiki fault systems show 

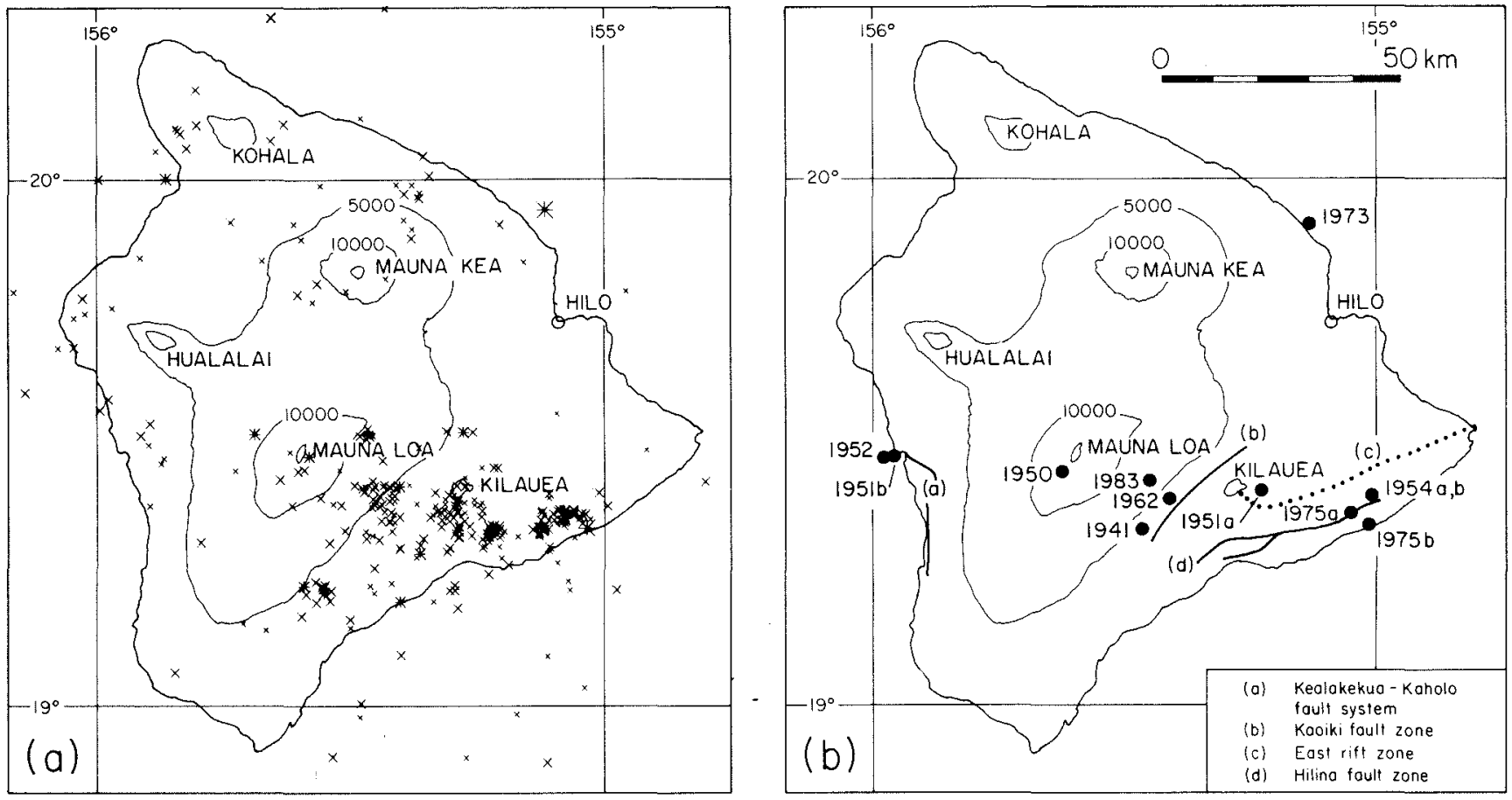

Fig. 1. (a) Seismicity of the island of Hawaii, from the NOAA catalog. Events are those with $M_{L} \geqslant 3.5$ from 1970 to 1981. Small crosses indicate magnitudes less than 4.0; larger crosses, 4.0-4.9; asterisks, 5.0 and larger. Volcanic centers are named. (b) Map showing the locations of the 12 events chosen for the depth study and some fault zones of the island.

normal motion and were built up predominantly by largescale gravitational slumping of the volcanic flanks [Stearns, 1966; Swanson et al., 1976; Lipman, 1980]. In general, most of the earthquakes occur on the south part of the island, near the volcanic centers of Mauna Loa and Kilauea, or the volcanically active east rift zone of Kilauea, and near the Kaoiki and Hilina fault zones. The Kaoiki zone has numerous earthquakes, related to the tectonics of Mauna Loa's southeast flank and the relative activity of Mauna Loa versus Kilauea volcanism. Displacement of Kilauea's south flank occurs in the area of the east rift zone and the Hilina fault system and is the primary cause of earthquakes there [Swanson et al., 1976; Tilling et al., 1976; Koyanagi et al., 1972]. The first hypocenter studies on the island showed that most of the seismicity in the Kaoiki zone is $\leqslant 15 \mathrm{~km}$ deep; in the Hilina zone, $\leqslant 20 \mathrm{~km}$; in the east rift zone, about $10 \mathrm{~km}$; and under Kilauea, $\leqslant 60 \mathrm{~km}$ [Eaton and Murata, 1960].

We chose to study all earthquakes since 1940 with magnitudes of 6 and larger. The 12 selected events are shown in Figure $1 b$ and listed in Table 1. Magnitudes for the earthquakes from 1941 to 1954 are from Gutenberg and Richter [1954] or the Seismological Laboratory in Pasadena, California. These magnitudes (denoted by $M$ ) are usually equivalent to the standard $M_{S}$ [Geller and Kanamori, 1977]. The $m_{b}$ and $M_{S}$ magnitudes for the events between 1973 and 1983 are from the monthly bulletin Preliminary Determination of Epicenters published by the U.S. Geological Survey, and $M_{L}$ values are from the Hawaiian Volcano Observatory (HVO). In all cases, the locations listed are either estimated or instrumental epicenters assigned by HVO. The five earthquakes since 1962 have precisely determined hypocenters from the Hawaiian network; these events are used primarily as reference events for the depth estimates of the earlier earthquakes.

Descriptions of the pre-1960 study events were found in The Volcano Letters, compiled by the staff of the HVO [U.S. Geological Survey, 1925-1955]. The reports frequently contained information on isoseismal patterns, damage and surface cracking, estimated epicenters, and depth ranges of the earthquakes. In what follows, we briefly summarize this information. It should be noted that high-gain, short-period instruments did not begin operation on Hawaii until 1955. In 1950 there were only five seismic stations on the island, many of which were equipped only with horizontal instruments with longer response periods. These instruments were frequently rendered inoperable by shaking during the larger events. Synchronized time signals were just beginning in 1952 [Klein and Koyanagi, 1980]. Thus the earthquake locations (and certainly instrumental depths) prior to 1960 are of much lower quality than those of recent events.

September 25, 1941. This earthquake occurred on the southeast flank of the volcano Mauna Loa. The epicenter shown on Figure $1 b$ was estimated from the geographic description in The Volcano Letter 473. Although HVO did assign a depth of $11 \mathrm{~km}$, depth assignments in this period should be considered dubious due to the sparse instrumentation. (Routine depth assignments were discontinued in subsequent Volcano Letters from this period.)

May 30,1950. This event occurred on or below the upper southwest rift of Mauna Loa near its summit. Its occurrence in part caused the HVO to immediately release an eruption alert. Mauna Loa erupted 78 hours later, in one of its largest eruptions for at least 1000 years LMacdonald, 1954; Lipman, 1980]. Shaking disabled all of the instruments on the island, but intensity 6 was reported along the 
TABLE 1. Study Events

\begin{tabular}{|c|c|c|c|c|c|c|c|}
\hline Date & $m_{b}$ & $M$ or $M_{S}$ & $M_{L}$ & $\begin{array}{l}\text { Latitude } \\
{ }^{o} \mathrm{~N}\end{array}$ & $\begin{array}{c}\text { Longitude } \\
{ }^{\circ} \mathrm{W}\end{array}$ & $\begin{array}{l}\text { Estimated or } \\
\text { Instrumental } \\
\text { Depth, km }\end{array}$ & $\begin{array}{l}\text { Estimated Depth } \\
\text { From This } \\
\text { Study, km }\end{array}$ \\
\hline Sept. 25,1941 & & 6 & & 19.3 & 155.4 est." & $\approx 11$ & $35-40$ \\
\hline May 30,1950 & & $61 / 4$ & & 19.5 & 155.6 est. & -- & $>40$ \\
\hline April $23,1951 \mathrm{a}$ & & $61 / 2$ & & 19.4 & 155.2 est. & $\approx 40-50$ & $35-40$ \\
\hline Aug. $21,1951 \mathrm{~b}$ & & 6.9 & & 19.5 & 155.9 est. & -. & $20-25$ \\
\hline May 23, 1952 & & 6.0 & & 19.48 & 155.98 inst. & $\approx 10$ & $\approx 40$ \\
\hline March $30,1954 a$ & & 6.0 & & 19.4 & 155.0 est. & $\approx 20$ & $20-25$ \\
\hline March $30,1954 b$ & & 6.5 & & 19.4 & 155.0 est. & $\approx 20$ & $\approx 10$ \\
\hline June 28,1962 & & $53 / 4$ & 6.1 & 19.40 & 155.41 inst. & 8 & $25-30$ \\
\hline April 26, 1973 & 6.0 & 6.1 & 6.2 & 19.90 & 155.13 inst. & 45 & $\approx 40$ \\
\hline Nov. 29,1975 a & 5.8 & 5.1 & 5.7 & 19.37 & 155.04 inst. & 10 & $25-30$ \\
\hline Nov. $29,1975 b$ & 6.0 & 7.1 & 7.2 & 19.35 & 155.01 inst. & 10 & $10-15$ \\
\hline Nov. 16,1983 & 6.4 & 6.7 & 6.6 & 19.43 & 155.45 inst. & 12 & $15-20$ \\
\hline
\end{tabular}

*Indicates whether the epicenter is estimated (est.) or instrumental (inst.).

western coast. No depth estimate was given. We checked the basis of the $61 / 4$ magnitude figure by examining the supporting notepads for Gutenberg and Richter [1954] [Goodstein et al., 1980]. We found that this was assigned from the amplitude of the Pasadena record only. However, the other events in this study with comparable body wave amplitudes on the Pasadena instrument had magnitudes between $53 / 4$ and 6.9 that were assigned on the basis of more than one station.

April 23, 1951. This earthquake was located just east of the crater of Kilauea. Based on the uniformity of intensity distribution, a depth estimate of $40-50 \mathrm{~km}$ was given [Macdonald, 1954]. The epicenter and depth estimates were noninstrumental. However, a moderate foreshock $11 \mathrm{~km}$ away was assigned a depth of $34 \mathrm{~km}$. A magnitude of 6.5 was assigned at Pasadena. Kilauea had been quiet since 1934 but erupted 14 months after the occurrence of this earthquake. To our knowledge, this earthquake and the 1950 Mauna Loa event are the largest events in such close spatial association with the active volcanoes.

August 21, 1951. This earthquake was located along the Kona (western) coast near the Kealakekua fault system. Again, there was no instrumental epicenter or depth information. Most of the aftershocks aligned closely with the surficial expression of the fault. Tsunami activity was reported throughout the Hawaiian Islands [Macdonald and Wentworth, 1951]. Gutenberg and Richter [1954] reported magnitude 6.9 and a depth of about $60 \mathrm{~km}$. From the notepads we found that this depth was inferred by adjusting the magnitude determined from the surface waves, $M$, until it equalled the magnitude determined from the body waves, $m$, at 6.9. However, a comparison of the isoseismal patterns from this earthquake and the April 1951 Kilauea event clearly indicates that the Kona earthquake was the shallower (Figure 2).

May 23, 1952. This event was very close to the 1951 Kona earthquake, perhaps an aftershock on the Kealakekua fault. HVO reported a depth of about $10 \mathrm{~km}$. The magnitude at Pasadena was 6.0 (Volcano Letter 516).

March 30, 1954. The two earthquakes on this date were near the east shore of Hawaii along the east rift zone of Kilauea. HVO reported depths of about $24 \mathrm{~km}$. Magni- tudes given by Pasadena were 6.0 and 6.5 (Volcano Letter 523). A large eruption began from the east rift zone the following February.

June 28, 1962. Each of the earthquakes after 1960 was the subject of one or more studies. The June 28, 1962 event was among the smallest considered in this study $\left(M_{S}\right.$ $\approx 53 / 4$, assigned at Berkeley). It was included because of its location near the recent earthquake in November 1983; both were located in the Kaoiki zone of the east flank of

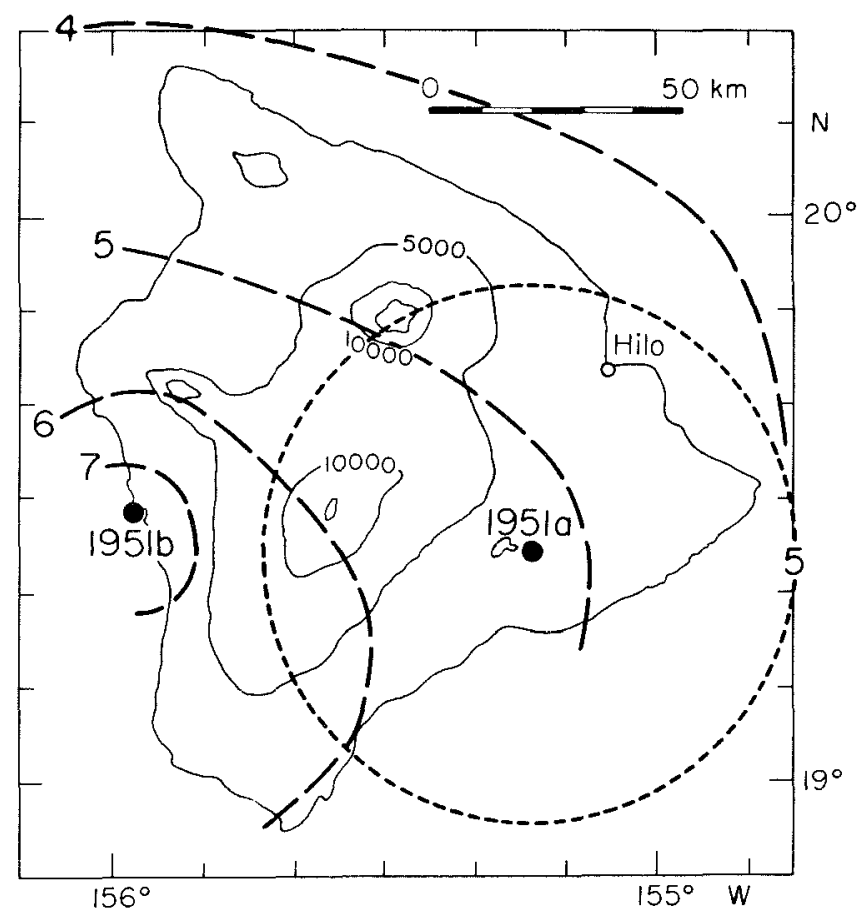

Fig. 2. Comparison of isoseismal contours from the April 1951 Kilauea earthquake (1951a) and the August 1951 Kona earthquake (1951b). Intensities from the Kilauea earthquake were uniform for a radius of $50 \mathrm{~km}$, suggesting a large depth, estimated at $40-50 \mathrm{~km}$. Contours from the Kona event fall off more rapidly with distance from the epicenter, indicating a shallower depth. (Isoseismal contours for the Kona earthquake were redrawn from Macdonald and Wentworth [1951].) 


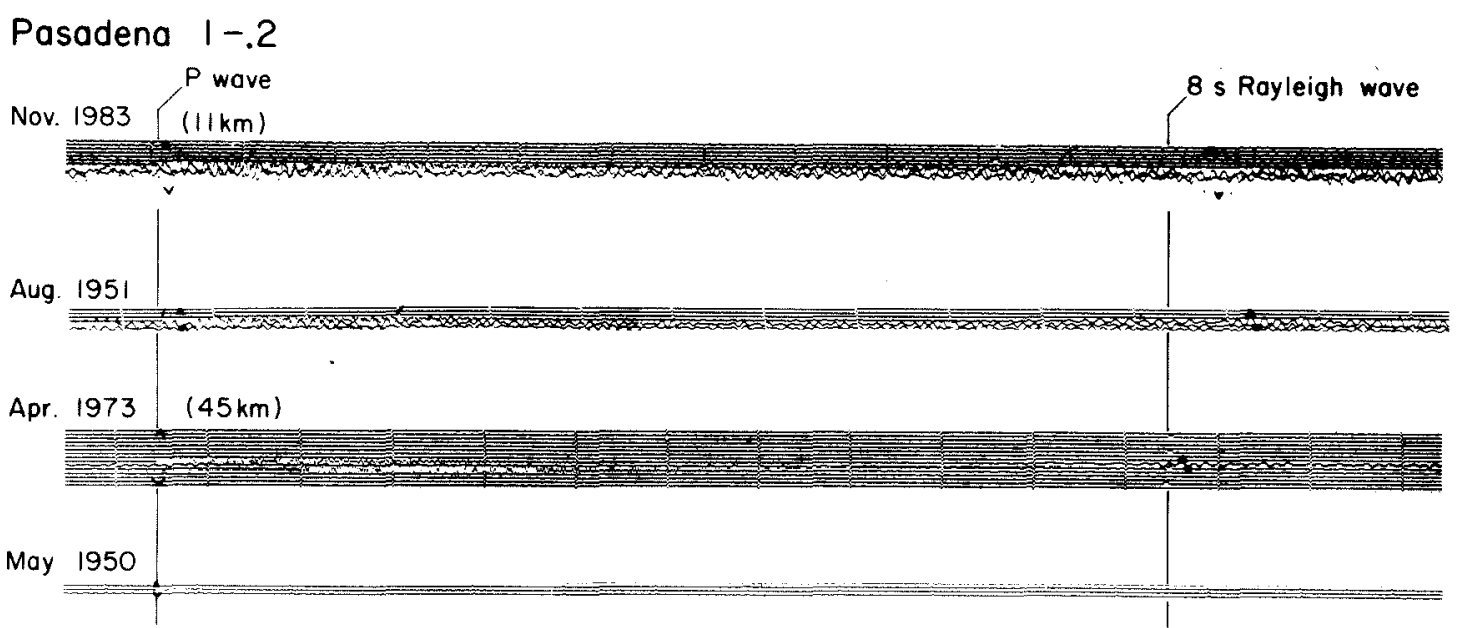

Fig. 3. Portions of records of the November 1983 Kaoiki, August 1951 Kona, April 1973, and May 1950 Mauna Loa earthquakes from the short-period (1-0.2) vertical instrument at Pasadena. The depths of the 1983 and 1973 earthquakes are known to be $12 \mathrm{~km}$ and $45 \mathrm{~km}$, respectively. The body waves of these two events have comparable amplitudes, but the surface waves are much smaller for the deeper earthquake. Note that the $P$ wave of the Mauna Loa event is one half that of the Kona event, but the Rayleigh waves are undiscernable. The width of the seismogram strips is $15 \mathrm{~min}$; tick marks are $1 \mathrm{~min}$.

Mauna Loa. The depth was well constrained at $8.1 \mathrm{~km}$ [Koyanagi et al., 1966].

April 26, 1973. This earthquake, $M_{S}=6.1$, was located off the northeast shore of Hawaii, away from most of the island's seismic activity. Detailed studies involving crustal velocity structures and station corrections, and intricate body wave modeling, gave this event depths of $48 \pm 7$ $\mathrm{km}$ and $42 \mathrm{~km}$, respectively [Unger and Ward, 1979; Butler, 1982]. This is the only large deep event to have occurred since local instrumentation was installed in the late 1950 's.

November 29, 1975 (the Kalapana earthquake). This event had the largest instrumental magnitude to date of all Hawaiian earthquakes $\left(M_{S}=7.1\right)$. The Kalapana earthquake and its magnitude 5.2 foreshock had depths of about $10 \mathrm{~km} \mathrm{LAndo,} \mathrm{1979;} \mathrm{Crosson} \mathrm{and} \mathrm{Endo,} \mathrm{1981].} \mathrm{The} \mathrm{earth-}$ quake occurred on the south flank of Kilauea along the Hilina fault system and involved a large crustal subsidence over the area between Kilauea's summit and the coast [Tilling et al., 1976]. It also caused large tsunamis in the Hawaiian Islands. The mechanism may be interpreted either as a very shallow dipping normal fault or as a large landslide or detachment event, brought on by repeated magma injection into the east rift zone [Ando, 1979; Furumoto and Kovach, 1979; Nakamura, 1980; Eissler and Kanamori, 1985]. The March 1954 earthquakes occurred in the same general area.

November 16, 1983 . This earthquake, $M_{S}=6.6$, was located near Mauna Loa in the Kaoiki zone. Its occurrence raised considerable interest in light of renewed seismic and inflation activity over several years at Mauna Loa. Mauna Loa had been quiet for many years after the 1950 eruptive phase, until a resurgence in both shallow and deep seismicity in 1974 [Koyanagi et al., 1975]. A brief but voluminous eruption occurred in July 1975. Earthquakes continued at a low level until mid-1980, when both shallow and deep seismicity began to rise [Decker et al., 1983]. Extension rates also increased, indicating a growing volume of magma in the shallow reservoirs. Mauna Loa subse- quently began to erupt on March 25, 1984; this eruption is being compared in size to that of 1950 . The preliminary depth assigned to the earthquake was $12 \mathrm{~km}$ [Decker and Koyanagi, 1984].

Seismograms from the vertical Benioff short-period $\left(T_{p}\right.$ $=1 \mathrm{~s}, T_{g}=0.2 \mathrm{~s}$, Gain $\left.\approx 100,000\right)$ and long-period $\left(T_{p}=\right.$ $1 \mathrm{~s}, T_{g}=90 \mathrm{~s}$, Gain $\approx 3,000$ ) instruments at Pasadena were available for all 12 earthquakes. For illustrative purposes, we show complete sections of seismograms of four selected earthquakes in Figures 3 and 4: the shallow 1983 Kaoiki event, the August 1951 Kona earthquake, the deep 1973 event, and the May 1950 Mauna Loa earthquake. On the short-period records (Figure 3), the 1983 earthquake has large 8-s Rayleigh waves arriving $11 \mathrm{~min}$ after the $P$ wave. Note that the amplitude of the body waves of the 1973 event is the same as for the 1983 earthquake, but the 8-s surface waves are only one tenth as large. The surface wave amplitude from the 1951 Kona earthquake is intermediate to the 1983 and 1973 events. Although the $P$ wave from the 1950 Mauna Loa event is comparable in size to the Kona event (about one half as large), its Rayleigh waves are at noise level.

The long-period 1-90 records in Figure 4 show a similar pattern. The largest signal from the 1983 event is the 8 to 10-s Rayleigh wave train, which arrives between 11 and 12 min after the $P$ wave and then goes offscale. The 8 -s waves are also the largest-amplitude signal for the 1951 Kona earthquake. However, this wave period is entirely suppressed in the 1973 record; instead, there is a distinctive train of Rayleigh waves with a period of about $20 \mathrm{~s}$, arriving 9 min after the $P$ wave. On close inspection, some 20-s energy can be seen at about $9 \mathrm{~min}$ for the 1983 and 1951 events, but it is clearly enhanced for the 1973 earthquake. Note that, as on the short-period records, the amplitudes of the body waves of the 1983 earthquake and the 1973 earthquake are roughly equal. The signal on the $1-90$ record of the May 1950 earthquake is very small, but although the body wave is clearly visible, there is no discernible 20-s 


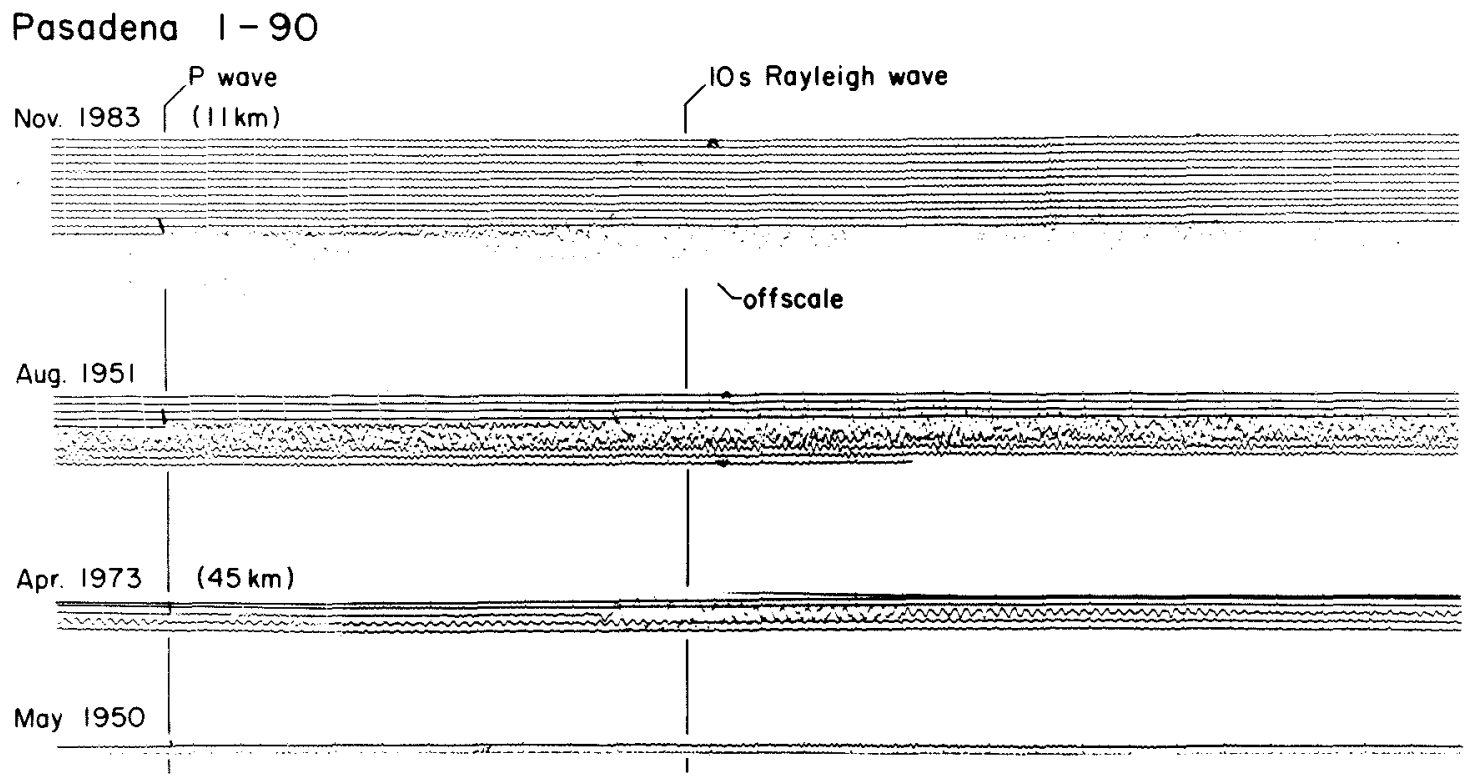

Fig. 4. Long-period (1-90) vertical seismograms for the same events as in Figure 3. The dominant signal on the 1983 Kaoiki and 1951 Kona records is the 8-s Rayleigh wave, which is supressed for the 1973 event. Instead, the 1973 record has a strong enhancement of 20 -s waves. Smaller 20 -s waves with the same group velocity are noticeable in the 1983 and 1951 records. The Mauna Loa record shows no 20-s energy. The width of the seismograms is 30 min; tick marks are $1 \mathrm{~min}$.

wave. From these examples, it appears that the excitation of Rayleigh waves in the period range of $8-20 \mathrm{~s}$ is sensitive to differences in focal depth of about $50 \mathrm{~km}$ or less.

Portions of the short-period seismograms containing the body waves and the 8 to 10 -s surface waves for all the study events are reproduced in Figure 5. The large 1975 Kalapana earthquake has high-amplitude surface waves and a body wave nearly as large, although the maximum in the body wave train is about $30 \mathrm{~s}$ after the signal onset. The surface waves from the $1954 \mathrm{~b}$ event are twice as large as its body waves. The foreshock to the Kalapana earthquake, event 1975a, and events 1954a and 1962 all have similar body and surface wave amplitudes. The 1941 record is very different from the others, with a large distinctive body wave but a small Rayleigh wave. The body wave signals on the 1952 and 1951a records are about the size of the 1975a, 1954a, and 1962 group, but the surface waves are significantly smaller; those of the 19 1a earthquake are only slightly above noise level. Since Rayleigh wave excitation decreases with source depth, we expect that events with very small surface waves, such as the 1941 earthquake, the 1951a Kilauea earthquake, and the 1950 Mauna Loa earthquake, are deeper than events with large surface waves, such as the 1983 Kaoiki, 1951 Kona, and 1975 Kalapana earthquakes. This observation can be quantified by calculating the excitation of Rayleigh waves as a function of source depth.

\section{ANALYSIS}

\subsection{Surface Wave Excitation Amplitudes}

To model the excitation of Rayleigh waves as a function of depth, we computed the eigenfunctions describing the radial and horizontal components of displacement and stress in a nongravitating, spherically layered earth. We fol- low the method described by Bolt and Dorman [1961]. The calculation was done for the two dominant periods in the Rayleigh waves on the Pasadena seismograms, $8 \mathrm{~s}$ and $20 \mathrm{~s}$. A composite velocity structure was used, consisting of the model used by HVO in their hypocenter locations above 40 km [Tanigawa et al., 1983], and an average oceanic model below $40 \mathrm{~km}$ [Ben-Menahem et al., 1970]. This velocity structure has the Moho discontinuity at $15 \mathrm{~km}$. To check the sensitivity to structure, eigenfunctions were calculated for another crustal model of Hawaii with the Moho at 13.5 $\mathrm{km}$ (model C of Ward and Gregersen [1973]). The difference in the amplitude of the eigenfunctions was $6 \%$ at $8 \mathrm{~s}$ and negligible at $20 \mathrm{~s}$. Crustal structure studies on the island of Hawaii show that the depth to Moho varies from about $12 \mathrm{~km}$ to about $15 \mathrm{~km}$ under the active volcanic centers [Hill, 1969; Crosson and Koyanagi, 1979].

The spectrum of the vertical component of Rayleigh wave motion from a double-couple source is proportional to the "excitation functions" $P_{R}^{(1)}, S_{R}^{(1)}$, and $Q_{R}^{(1)}$ as follows:

$$
\left(s_{R} S_{R}{ }^{(1)}+p_{R} P_{R}^{(1)}+i q_{R} Q_{R}{ }^{(1)}\right)
$$

where the coefficients $p_{R}, s_{R}$, and $q_{R}$ are simple trigonometric functions of the fault dip, slip, and strike angles [BenMenahem et al., 1970]. The excitation functions are simple combinations of the displacement and stress eigenfunctions, as given by Kanamori and Stewart [1976].

Once the excitation functions are determined from the eigenfunctions, it is simple to calculate the excitation amplitude expected for a given fault geometry and source depth. However, for the earthquakes in this study before 1960, focal mechanism information is incomplete or absent. Further, the waves with periods of $20 \mathrm{~s}$ and less are likely to suffer severe ray path refractions, so that a precise mechanism may not adequately explain the amplitude variation 


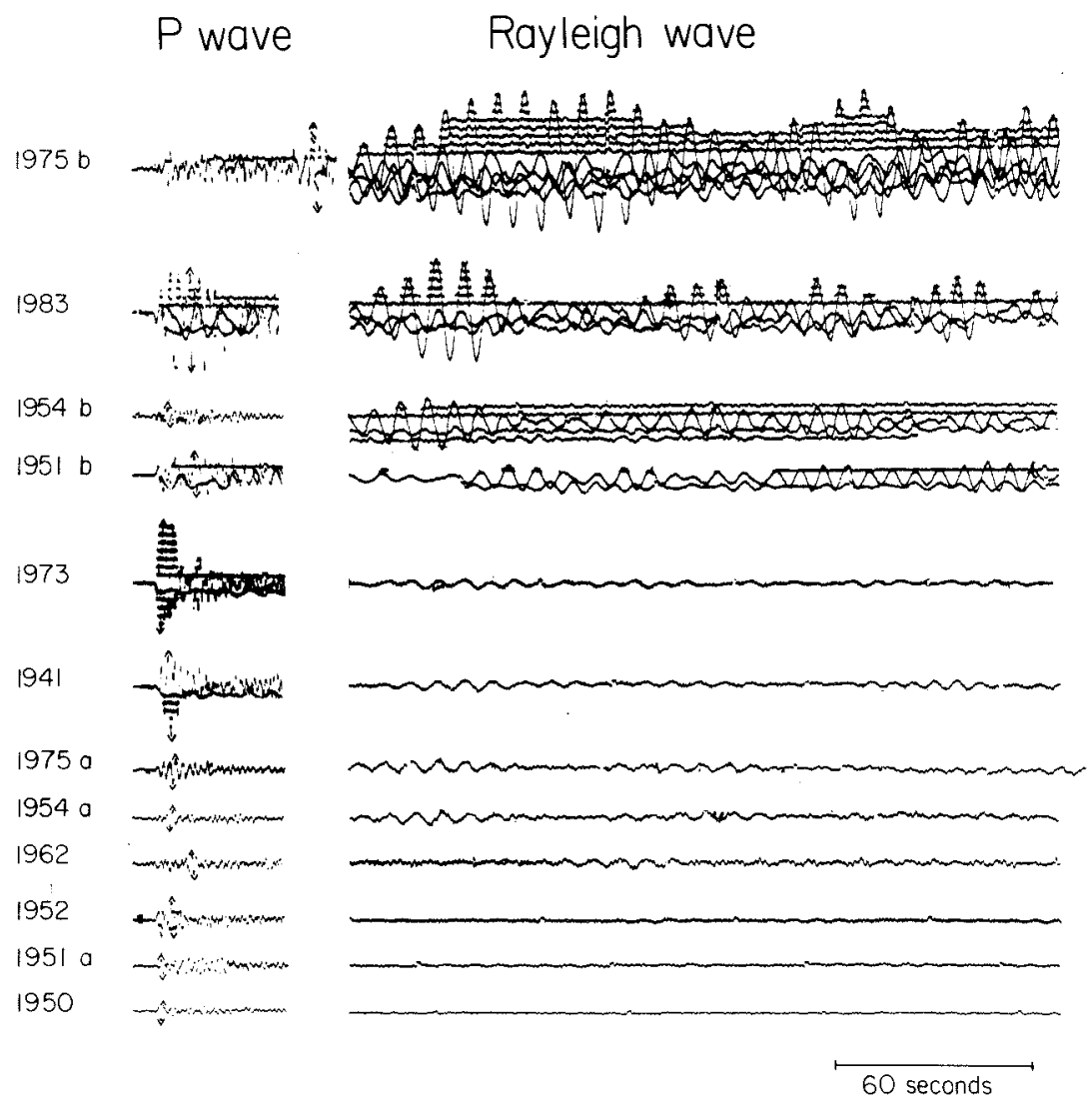

Fig. 5. Portions of the short-period records from the 12 study events, showing the $P$ waves and Rayleigh wave trains. The Rayleigh wave sections begin $11 \mathrm{~min}$ after the $P$ wave arrival (group velocity $\approx 3.7 \mathrm{~km} \mathrm{~s}^{-1}$ ). Note the difference between the relative amplitudes of the body and surface waves.

with azimuth. As an overall calcuation, we determined the range of excitation expected from three basic faults: a pure strike-slip fault on a vertical fault plane, a pure dip-slip fault on a vertical fault plane, and a pure dip-slip fault on a fault plane dipping at $45^{\circ}$. Evaluating the cofficients in (1), the mechanism-dependent part of the spectrum is given by $P_{R}{ }^{(1)} \sin 2 \theta,-i Q_{R}{ }^{(1)} \sin \theta$, and $1 / 2\left(S_{R}{ }^{(1)}-P_{R}{ }^{(1)} \cos 2 \theta\right)$, respectively, for the three faults, where $\theta$ denotes the azimuth. To determine a general value for each fault, we take the azimuthal average by integrating the absolute value of the excitation over one cycle of $\theta$. The azimuthally averaged excitation, $|\overline{E x}|$, for the three basic faults is then

\begin{tabular}{|c|c|}
\hline Vertical strike slip & $\frac{2}{\pi}\left|P_{R}^{(1)}\right|$ \\
\hline Vertical dip slip & $|\overline{E x}| \propto \frac{2}{\pi}\left|Q_{R}^{(1)}\right|$ \\
\hline $45^{\circ}$ dip slip & $\frac{1}{2}\left|S_{R}^{(1)}\right|$ \\
\hline
\end{tabular}

The averaged excitation amplitudes are plotted as a function of depth for the 8-s and 20-s cases in Figure 6. In the 8-s case the excitation falls off dramatically with depth; amplitudes excited by a source at $50 \mathrm{~km}$ are roughly 300 times smaller than those excited by a source at $10 \mathrm{~km}$ depth. The effect of the fault geometry on the excitation is much smaller; at $10 \mathrm{~km}$ depth the maximum amplitude difference between the azimuthally averaged faults is a factor of 4 . Above about $8 \mathrm{~km}$, the functions vary rapidly and are very sensitive to any change in the shallow crustal structure. We judge that the calculation is not accurate for extremely shallow depths. The excitation was calculated for a unit seismic moment of $1 \times 10^{27} \mathrm{dyn} \mathrm{cm}$.

At $20 \mathrm{~s}$ the excitation varies much more slowly with the source depth (Figure $6 b$ ). Unlike the 8-s case, the effect of focal mechanism on the excitation amplitude is severe at lower crustal and shallow mantle depths, where the functions $P_{R}{ }^{(1)}$ and $S_{R}{ }^{(1)}$ have zero crossings whose locations are fairly stable with respect to changes in the velocity structure. For example, it is possible for a pure vertical dip-slip fault at $20 \mathrm{~km}$ depth to have large $20-\mathrm{s}$ excitation, whereas a pure vertical strike-slip fault would have virtually none. Since most fault geometries have components of each of the basic faults, 20-s excitation will be small for some events above $25 \mathrm{~km}$. The excitation for all three faults reaches a broad maximum between depths of 30 and $45 \mathrm{~km}$ and decays only by a factor of $2-3$ by $70 \mathrm{~km}$. The expected maximum fits well with the records shown in Figure 4, where the 1973 earthquake $(h \approx 45 \mathrm{~km})$ had a relative enhancement of 20 -s energy. Tréhu et al. [1981] calculate excitation functions at selected source depths and $T=20 \mathrm{~s}$ for an oceanic structure with the Moho at $9 \mathrm{~km}$. The two sets of functions agree very well in terms of location of maxima, shape of fall-off, and relative amplitudes. 

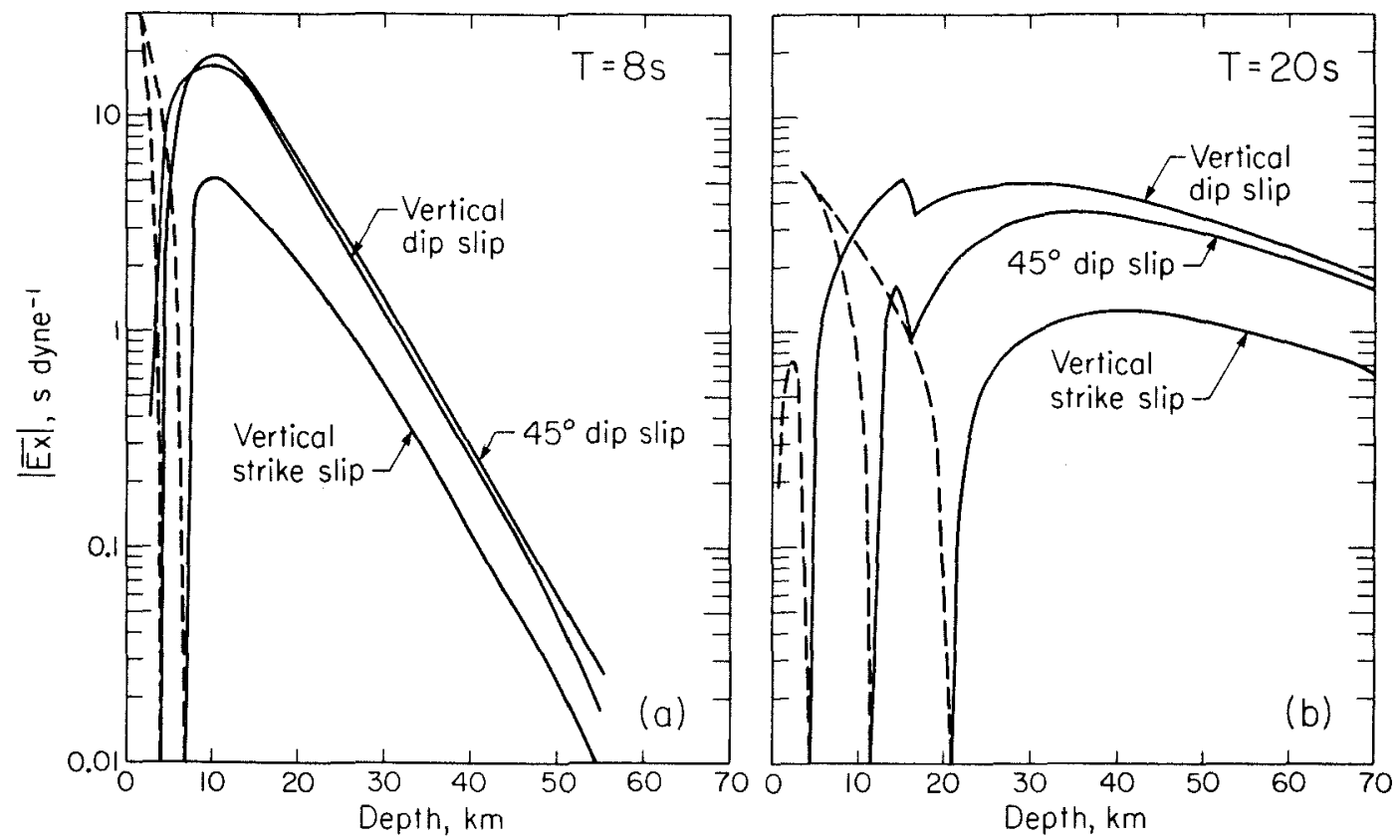

Fig. 6. (a) Absolute values of amplitudes of the azimuthally averaged excitation, for the three basic faults, versus source depth at $T-8 \mathrm{~s}$. (Dashed lines indicate where the values are negative.) The excitation is scaled to a source strength of $10^{27} \mathrm{dyn} \mathrm{cm}$. The excitation at $50 \mathrm{~km}$ source depth has decreased 300 times from the maximum value at $10 \mathrm{~km}$, while the maximum range introduced by the effect of fault geometry is a factor of 4 . The calculation is judged unreliable for depths above $8 \mathrm{~km}$. (b) Excitation amplitudes versus source depth at $T=20 \mathrm{~s}$. The excitation reaches a broad maximum at $35-40 \mathrm{~km}$, and has decreased only by a factor of 3 at $70 \mathrm{~km}$. The range from the fault geometry is a factor of 3-4 at the excitation maximum. Fault geometry can have a severe effect at lower crustal and midmantle depths, where the function cross zero.

\subsection{Effect of Body Waves}

To describe the body wave amplitudes, synthetic $P$ wave seismograms for the three basic faults were computed for a near-surface focus, following the method in Kanamori and Stewart [1976]. We include the contribution from the direct $P$ wave and the surface reflections $p P$ and $s P$ for a half-space and apply the 1-0.2 instrument response. Once again, the average value of the azimuthal radiation pattern was used. For the vertical strike-slip fault and the vertical
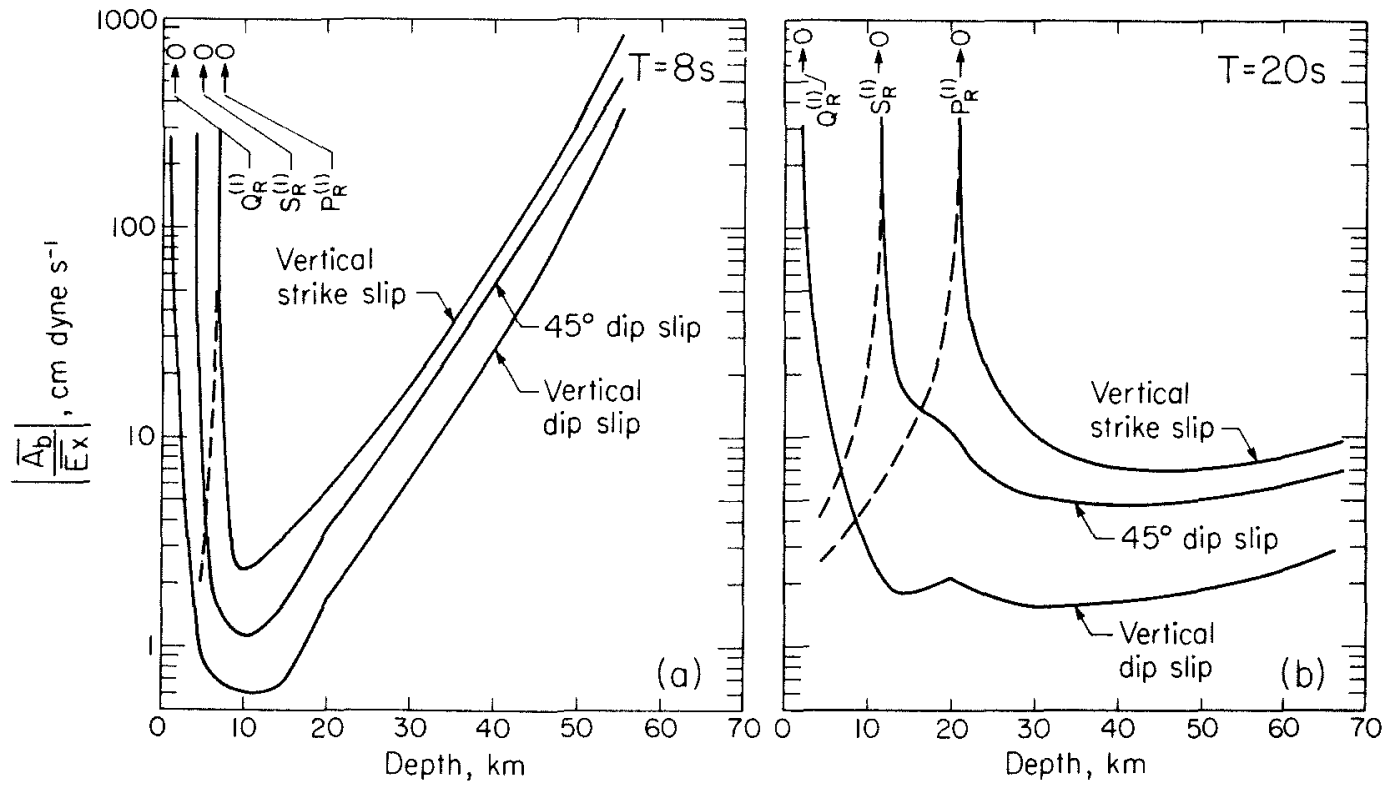

Fig. 7. (a) Absolute values of the azimuthally averaged excitation ratios versus source depth, for the three fault geometries, at $8 \mathrm{~s}$. The excitation is scaled to a source strength of $10^{27}$ dyn $\mathrm{cm}$. (The large values above $8 \mathrm{~km}$ should be disregarded.) The ratios steadily increase by a factor of 200 from 10 to $70 \mathrm{~km}$. (b) Excitation ratios versus source depth at $20 \mathrm{~s}$. Note that ratios may become large for some fault geometries at lower crustal and shallow mantle source depths. 


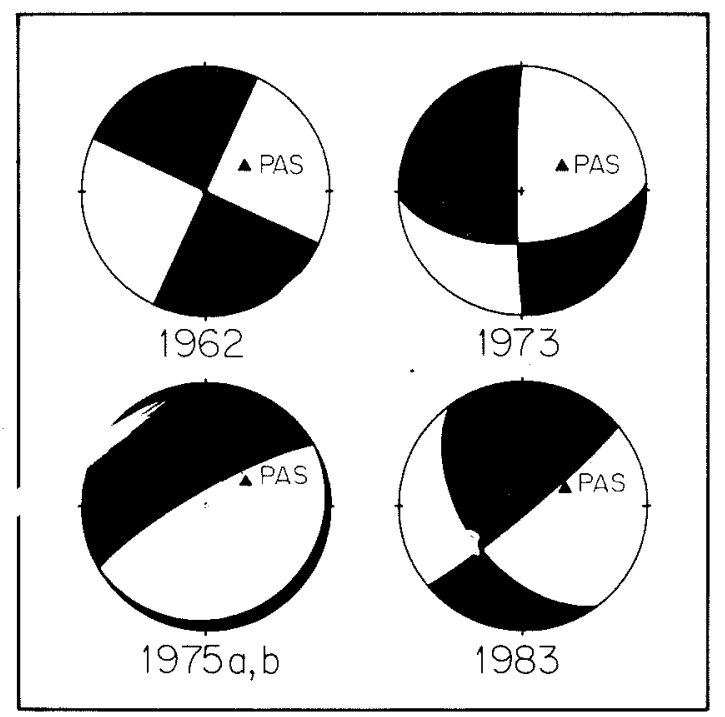

Fig. 8. Focal mechanisms for the five post-1960 events. The location of Pasadena on the focal sphere is indicated by a triangle. Mechanisms are from the following sources: 1962, Koyanagi et al. [1966]; 1973, Butler [1982]; 1975a and b, Ando [1979]; 1983, Decker and Koyanagi [1984].

dip-slip fault, the azimuthal dependence is $\sin 2 \theta$ and $\sin \theta$, respectively. For the $45^{\circ}$ dip-slip fault, the azimuthal pattern is a function of takeoff angle and can be evaluated and averaged for the appropriate Hawaii-Pasadena value $\left(31^{\circ}\right)$. The range in the azimuthally averaged body wave amplitudes for these three fault geometries is between a factor of 2-3.

Theoretically, for a given seismic moment, body wave amplitudes diminish somewhat with source depth as velocity increases. In assigning magnitudes from body waves, Gutenberg devised empirical charts to describe this effect [Richter, 1958, Appendix 8]. We use these to modify the surface-focus amplitudes for various source depths. This is a small effect; at $60 \mathrm{~km}$ depth the amplitude is about 0.6 times the surface value. Since the interference pattern between the direct and reflected rays changes with depth, it can also influence the amplitude somewhat, but this effect was not included.

\subsection{Excitation Ratios}

We define the excitation ratio as the azimuthally averaged peak-to-peak synthetic body wave amplitude, $A_{b}$, divided by the absolute value of the azimuthally averaged surface-wave excitation, $|\overline{E x}|$, both for the same basic fault. The ratios are controlled by the fall-off of the surface wave excitation, although the body wave fall-off has a slight effect. Both the $A_{b}$ and $|\overrightarrow{E x}|$ calculations are scaled to the same unit seismic moment, so that taking the ratio eliminates the moment and allows direct comparison of ratios between the study events. It should be noted that the surface wave excitation $|\overline{E x}|$ is calculated at the source location and does not include the effects of propagation, attenuation, or instrument. However, since the path and instrument are common to all events, the difference between $\left|A_{b} / \overline{E x}\right|$ and the measured ratio $A_{b} / A_{s}$ will be a constant correction factor, which can be found by comparing the observed and cal- culated ratios of the earthquakes with well-determined hypocenters.

The calculated ratios versus depth are shown in Figure 7. For the 8-s case the ratio at $50 \mathrm{~km}$ is about 200 times larger than at $10 \mathrm{~km}$. The values above $10 \mathrm{~km}$ should be disregarded as before. For the 20-s case the effect of focal mechanism is larger than the effect of depth between 30 and $70 \mathrm{~km}$. The $20-\mathrm{s}$ observations will not be as diagnostic of depth as the 8-s observations, due to both the local, mechanism-dependent singularities at $10-25 \mathrm{~km}$, and the rather slight increase of the excitation ratios over the depth range of interest for Hawaiian earthquakes.

\subsection{Excitation Ratios for Events With Known Focal Mechanisms}

The five events since 1960 have known focal mechanisms from either the HVO network or teleseismic studies. The mechanisms are shown in Figure 8. Exact theoretical values of $|E x|$ and $A_{b}$, without azimuthal averaging, were evaluated for these specific mechanisms. $|E x|$ is now defined as the modulus of equation (1), evaluated for the correct trigonometric coefficients $p_{R}, s_{R}$, and $q_{R}$. Figure 9 shows the values of $|E x|$ and $\left|A_{b} / E x\right|$. The band defined previously by the three basic faults is indicated by heavy dashed lines. For the 1962 and 1973 mechanisms, the surface wave excitation $|E x|$ falls within the band of the three basic faults, and for the 1975a, 1975b, and 1983 mechanisms, $|E x|$ is slightly below the band (Figure $9 a$ ). However, Pasadena is located essentially in the nodal azimuth for these two mechanisms, causing the low values (Figure 8). When the theoretical $A_{b}$ is considered, the excitation ratios $\left|A_{b} / E x\right|$ for all five events fall within the basic fault band, even though Pasadena is near-nodal for two of the mechanisms (Figure $9 b$ ). Thus the ranges of $|\overline{E x}|$ and $A_{b}$ found by the general fault calculations provide reasonable estimates of the theoretical excitation for various fault geometries. Again, we point out that the azimuthally averaged general calculations may be more realistic due to the scattering of short-period waves.

\subsection{Depth Estimates}

The peak-to-peak amplitudes in millimeters of the observed records are listed in Table 2 . Both the $A_{b}$ and $A_{s}$ values were measured from the shorter-period $1-0.2$ instrument for comparison with the calculations. Surface wave information at $20 \mathrm{~s}$ on the 1-90 records was incomplete; energy was absent for some events, and the periods of identifiable signals ranged from 16 to $24 \mathrm{~s}$. On the shortperiod instrument the maximum surface wave energy was always between periods of 8 and $10 \mathrm{~s}$. The observed body wave amplitudes of the earthquakes are plotted versus the observed surface wave amplitudes in Figure 10. The bands indicate where the excitation ratio ranges for various source depths, as calculated in section 3.3, would fall on this plot. The correction to the calculated ratios, 0.36, was determined by forcing the 1973 and 1983 earthquakes to fall near the $45-\mathrm{km}$ and $10-\mathrm{km}$ depth bands, respectively. For the most part, the earthquakes correspond to depth bands in the way expected from qualitative examination of the character of the body and surface waves. The 1983 Kaoiki 

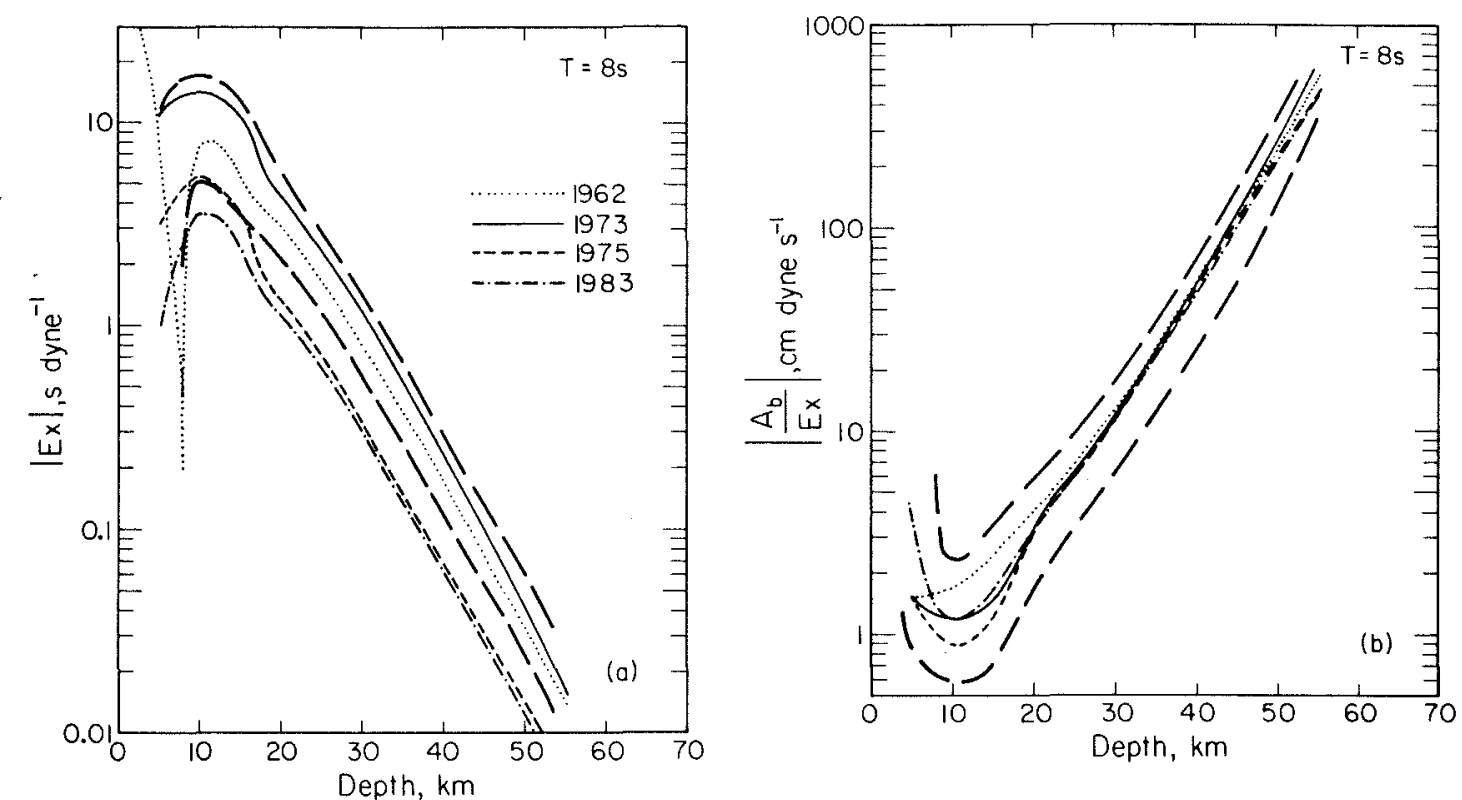

Fig. 9. (a) Modulus of the calculated 8-s surface wave excitation amplitude $E x$, as a function of source depth, evaluated for the five events with known focal mechanisms (events 1975a and 1975b had the same mechanism). The heavy, long dashed lines indicate the range of azimuthally averaged excitation amplitudes for the three basic faults. $(b)$ Excitation ratios vs source depth, where both $A_{b}$ and $E x$ have been evaluated for the known mechanisms. Note that the ratios fall within the range defined by the three basic faults.

and 1975 Kalapana earthquakes have crustal depths, as does the larger of the two events near Kalapana in 1954. The 1962 Kaoiki, 1951 Kona, and the foreshocks to the 1954 and 1975 Kalapana events group near a somewhat greater depth, about $25-30 \mathrm{~km}$. Figure 10 suggests a depth gap between the under $30 \mathrm{~km}$ depth bands and the rest of the earthquakes. The 1952 and 1941 events fall in the same band as the deep 1973 earthquake, around $45 \mathrm{~km}$. The two events near the volcanic centers, 1950 and 1951a, have estimated depths of $>40 \mathrm{~km}$ and $>35 \mathrm{~km}$, respectively; the range in $A_{s}$ values is due to uncertainty in the measurment of very small amplitudes.

For three out of the five instrumentally located events, our estimated depth agrees well with the instrumental depth. For the remaining two events, however, our esti- mates are about 3 times larger. As Table 1 shows, these two events (the June 1962 Kaoiki earthquake, $M_{S}=53 / 4$, and the November 1975 Kalapana foreshock, $M_{S}=5.1$ ) have the smallest magnitudes (less than 6). The depth discrepancy can be explained in terms of the difference in the source spectrum. For an earthquake with $M_{S}=6$, empirical relations [e.g., Kanamori, 1977] give a source dimension of $5.7 \mathrm{~km}$ (radius of an equivalent circular fault) and a corner frequency of $0.23 \mathrm{~Hz}$ (corner period of about 4 s) through Brune's [1970] relation. Our depth estimates are based on the amplitude of "1-s" body waves and "8-s" surface waves. Hence for earthquakes with $M_{S}$ significantly smaller than 6 , the corner period moves toward the body wave period, increasing the ratio of the body wave to surface wave amplitude. This causes an overestimate of depth.

TABLE 2. Peak-to-Peak Amplitudes of Body and Surface Waves on the Short-Period (1-0.2) and Long-Period (1-90) Instruments

\begin{tabular}{|c|c|c|c|c|c|c|}
\hline Event & $\begin{array}{c}A_{b}(1-0.2), \mathrm{mm} \\
T \approx 1 \mathrm{~s}\end{array}$ & $\begin{array}{c}A_{s}(1-0.2), \mathrm{mm} \\
T \approx 8 \mathrm{~s}\end{array}$ & $\begin{array}{l}A_{s}(1- \\
T \approx 10 \mathrm{~s}\end{array}$ & $\underset{T \approx 20 \mathrm{~s}}{\mathrm{~mm}}$ & $m_{b_{(P A S)}}$ & $M_{S(P A S)}{ }^{*}$ \\
\hline 1941 & 25 & 3 & 15 & 2 & 6.6 & $(6.0)$ \\
\hline 1950 & 5 & $<0.5$ & 3 & $\approx 1$ & 5.9 & $(5.2)$ \\
\hline $1951 \mathrm{a}$ & 5 & $<1$ & 3 & $\approx i$ & 5.8 & $(5.4)$ \\
\hline $1951 \mathrm{~b}$ & 11 & 7 & 41 & 16 & 6.4 & 6.4 \\
\hline 1952 & 10 & 1 & 3 & $\approx 2$ & 5.9 & $(5.4)$ \\
\hline $1954 a$ & 5 & 4 & 14 & $\approx 1$ & 6.0 & 6.0 \\
\hline $1954 b$ & 5 & 15 & 62 & $\approx 5$ & 5.8 & 6.6 \\
\hline 1962 & 6 & 3 & 8 & $\approx 1$ & 5.7 & 5.8 \\
\hline 1973 & 32 & 3 & -- & 20 & 6.3 & (5.9) \\
\hline $1975 a$ & 8 & 4 & 13 & $\approx 1$ & 6.0 & 6.0 \\
\hline $1975 \mathrm{~b}$ & 25 & 43 & offscale & 17 & 6.7 & 7.1 \\
\hline 1983 & 28 & 31 & offscale & 20 & 6.6 & 6.9 \\
\hline
\end{tabular}

"Parentheses indicate a known or suspected deep hypocenter. 


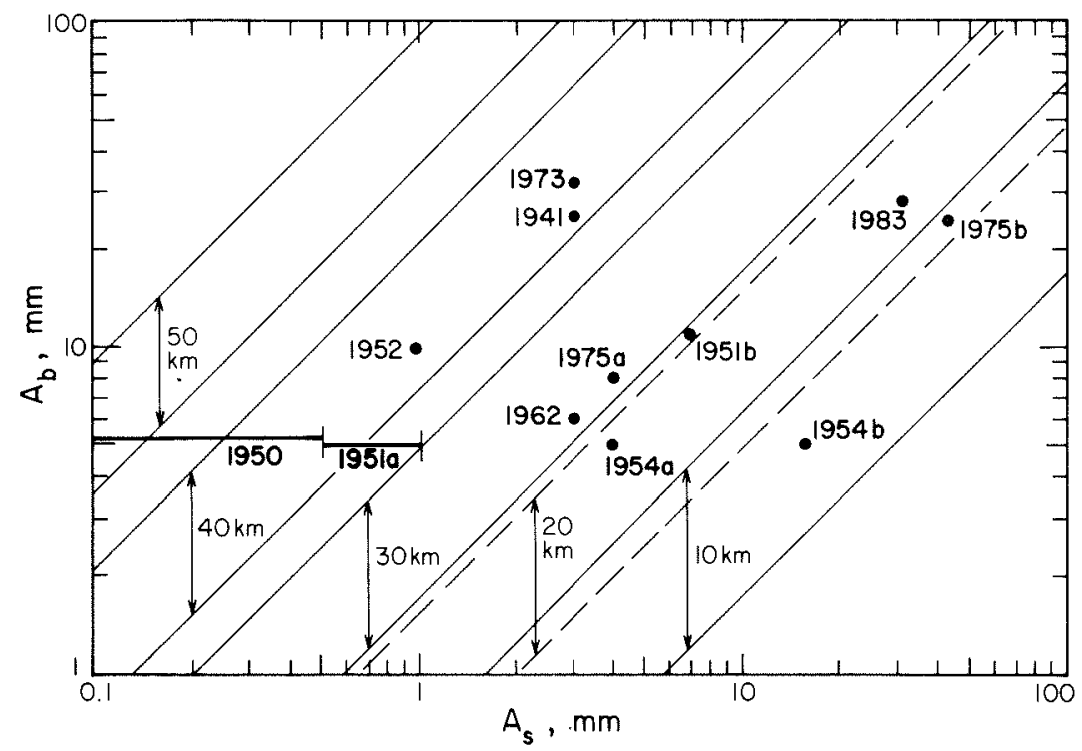

Fig. 10. Observed body wave amplitudes plotted versus observed surface wave amplitudes for the 12 study events. Bars for the 1950 and 1951 a events indicate estimates of very small amplitudes. The bands show where the ranges of the calculated ratios for various source depths fall on this plot.

Except for these two events, the earthquakes listed in Table 1 are large enough to avoid overestimation.

A few of the preinstrumental depths reported from other sources are in disagreement with the depth estimates. For example, the estimate for the 1951 Kona earthquake is shallow compared with that given by Gutenberg and Richter [1954]. However, a shallow depth is more consistent with the tsunami activity, and the earthquake's association with the Kealakekua fault. The 1941 earthquake appears deep by our method, but the HVO gave it a depth of $11 \mathrm{~km}$; however, the accuracy of an instrumental depth in that era is dubious. Some aftershocks to the 1941 event were given depths of $30 \mathrm{~km}$.

\subsection{Single Station Versus Global $M_{S}$}

An indication of the reliability of using surface wave amplitudes from a single station, i.e., Pasadena, can be obtained by comparing $M_{S}$ values derived from the Pasadena amplitudes alone to those based on many measurements worldwide. Body and surface wave magnitudes determined for the 12 events from the amplitudes on the 1-0.2 and 1-90 seismograms are listed in the last columns of Table 2. The formulas used are

$$
\begin{gathered}
m_{b}=\log \left(\frac{A}{T}\right)+Q(\Delta) \\
M_{S}=\log \left(\frac{A}{T}\right)+1.66 \log \Delta+3.3
\end{gathered}
$$

where $A$ is the maximum ground amplitude in microns for either the $P$ wave train or the surface wave, $T$ is the period of the maximum in seconds, $\Delta=36^{\circ}$ for Hawaii to Pasadena, and $Q(\Delta)=6.6$. Equation (4), from Vanek et al. [1962] was used instead of Gutenberg's standard formula because it includes a correction using $T$ for shorter-period surface waves. The values determined from the two instruments were averaged. The $M_{S}$ values in parentheses are for the earthquakes with a known or suspected deep hypo- center; we did not attempt to correct for depth. For the recent events, the $m_{b}$ and $M_{S}$ values agree fairly well with those reported by the National Earthquake Information Service (NEIS) (Table 1), implying that these one-station magnitudes may be representative for the pre- 1960 events as well. Note from the $m_{b}$ values that the two deep earthquakes under the volcanoes may have been smaller than previously reported (6.0 and 5.8 instead of $61 / 4$ and $61 / 2)$. The $m_{b}$ and $M_{S}$ for the Kona earthquake (1951b) agreed at 6.4 without a depth correction.

Figure 11 shows a comparison of $M_{S}$ values based on ground amplitudes at Pasadena with those assigned by NEIS from global readings, for a sample of 70 events in 19731974. On the average, the global values are only slightly larger ( 0.05 of a magnitude unit), and the standard deviation is 0.2 magnitude units. The overall agreement between $M_{S}$ and $M_{S_{\text {Pes }}}$ indicates that the Pasadena amplitudes are representative of the global values. This was an implicit assumption in the depth estimates. Even the extreme difference of 0.4 magnitude units between the Pasadena and

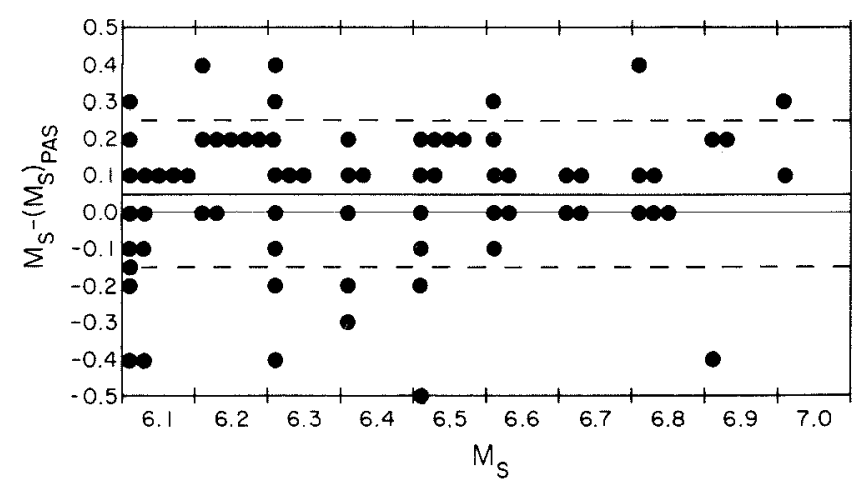

Fig. 11. Comparison between values of $M_{S}$ assigned from many stations, with values assigned from the ground amplitude at Pasadena only. The difference between $M_{S}$ and $M_{S_{(P A S)}}$ is plotted versus $M_{S}$. The average difference is 0.05 units, shown by the heavy solid line; the standard deviation is 0.2 units, shown by the dashed lines. 
global magnitudes, implying a surface wave amplitude difference of 2.5 , would change the depth estimates by only $10 \mathrm{~km}$ (see Figure 8).

\subsection{Mechanism Dependence of Global $m_{b}$}

An estimate of the effect of focal mechanism on amplitudes can be found by comparing the $m_{b}-M_{S}$ ratios for earthquakes with known focal mechanisms. Body wave amplitudes, and thus $m_{b}$, are expected to be much smaller for strike-slip events than for dip-slip events because of the proximity of the ray path direction to the nodal planes. Centroid moment tensor solutions have been routinely detemined for most events worldwide with $M_{S} \geqslant 5.0$ since 1977 [e.g., Dziewonski et al., 1985] (hereafter referred to as the Harvard catalog). We searched the Harvard catalog, from 1977 to December 1983 for strike-slip and dip-slip events in two depth ranges $0-20 \mathrm{~km}$ and $20-40 \mathrm{~km}$, where the depths were taken from the centroid hypocenter. Strike-slip events were defined as having a fault plane dip $\delta$ within $10^{\circ}$ of vertical, and a slip angle $\lambda$ within $10^{\circ}$ of right-lateral or left-lateral (i.e., $\lambda=0^{\circ} \pm 10^{\circ}$ or $180^{\circ} \pm 10^{\circ}$ ). Dip-slip events were defined as having fault plane dip $\delta$ between $25^{\circ}$ and $60^{\circ}$ and slip angle $\lambda$ within $10^{\circ}$ of thrust or normal $\left(\lambda=90^{\circ} \pm 10^{\circ}\right.$ or $\left.-90^{\circ} \pm 10^{\circ}\right)$. Figure 12 shows plots of $m_{b}$ versus $M_{S}$ for these mechanism groups in the two depth ranges, with a least squares line fit to the distrbutions. Although widely scattered, there is a marked difference between the $m_{b}-M_{S}$ relation for dip-slip and strike-slip events. For events between depths of 0 and 20 $\mathrm{km}, m_{b}$ is 0.31 magnitude units larger for dip-slip events than for strike-slip events at $M_{S}=6.0$ (Figures $12 a$ and $12 b$ ). This is equivalent to a factor of 2.1 in amplitude. Between 20 and $40 \mathrm{~km}$, the $m_{b}$ difference at $M_{S}=6.0$ has reduced to 0.12 magnitude units, or an amplitude factor of 1.3 (Figures $12 c$ and $12 d$ ). Recall that the range in the azimuthally averaged, synthetic body wave calcuation for the three basic faults was a factor of 2-3. If the mechanism dependence of $m_{b}$ found in the Harvard catalog is considered in the depth estimates, the largest factor (2.1) would change the estimates by less than $10 \mathrm{~km}$. Note that a factor of 2 is about the size of the bands defined by the azimuthally averaged basic fault calculations (Figure 10).

Thus two different effects have been examined in sections 3.6 and 3.7 using global data: (1) the accuracy of using a single station as representative of the surface wave amplitude at short periods, and (2) the mechanism dependence of observed body wave amplitudes. Both tests give an average range in amplitude of a factor of 2 to 2.5 , which is the same range previously estimated by the basic fault calculations.

\section{Discussion}

Estimated depths for both the 1951 Kilauea earthquake and the 1950 Mauna Loa earthquake were large $(\geqslant 35 \mathrm{~km})$. The 1950 earthquake was unique among the study events in having undiscernible Rayleigh wave signals on the shortperiod instrument (Figure 5). Rayleigh waves for the Kilauea earthquake were extremely small. This alone rules out the possibility that the earthquakes were shallow. Note from Figure 5 that if the amplitude of the long-period record of the deep $(48 \mathrm{~km}) 1973$ earthquake is reduced by a
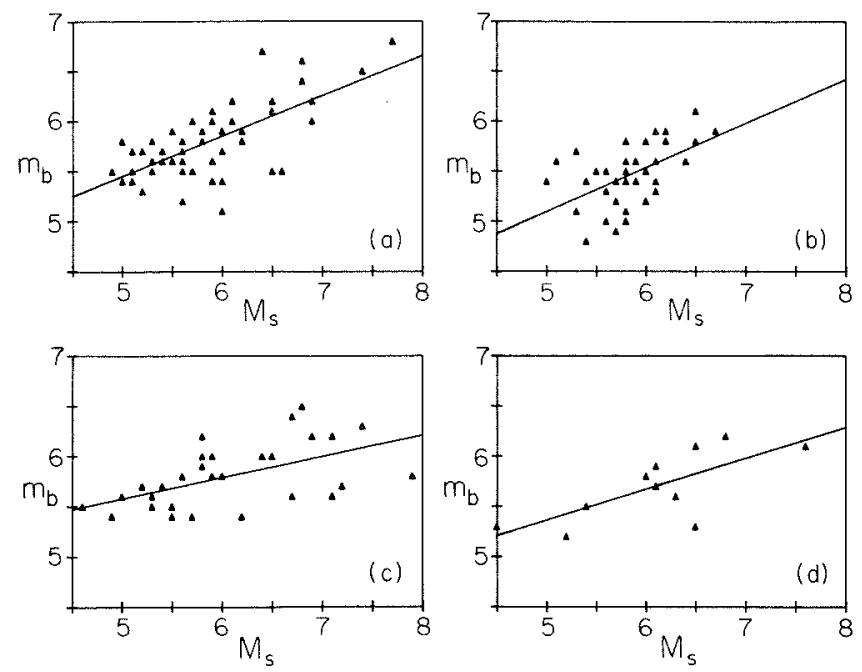

Fig. 12. (a) $m_{b}$ versus $M_{S}$ for all dip-slip events $(n-53)$ with depths between 0 and $20 \mathrm{~km}$ found in the Harvard catalog. (b) Strike-slip events, $n=37, h=0-20 \mathrm{~km}$. (c) Dip-slip events, $n=$ $30, h=20-40 \mathrm{~km}$. (d) Strike-slip events, $n=11, h=20-40 \mathrm{~km}$.

factor of 2 or 3, to be comparable with the $P$ wave amplitude of the 1950 event, the 20-s Rayleigh waves would still be clear. The lack of 20-s waves for the 1950 earthquake suggests that its depth is well removed from the maximum depth of excitation at 30-45 km. Extrapolating the 20-s excitation (Figure 6), amplitudes an order of magnitude less than those at $40 \mathrm{~km}$ would occur at source depths of 90 or $100 \mathrm{~km}$. However, the deepest seismicity reported for Hawaii is at $60 \mathrm{~km}$ [Eaton, 1962]. Examination of the 1980-1982 HVO catalogs suggests that this limit is actually around $50-55 \mathrm{~km}$ for well-located earthquakes. Recent studies have shown that for all oceanic intraplate earthquakes, the maximum depth of seismicity corresponds with the expected location of the $600^{\circ}-800^{\circ} \mathrm{C}$ isotherm, beyond which the lithosphere purportedly cannot fail in a brittle mode [Chen and Molnar, 1983; Wiens and Stein, 1983]. For Hawaii, this isotherm is put at $55-60 \mathrm{~km}$.

What is the significance that the two events under the volcanic centers and close in time to eruptions have greater depths than most other large earthquakes? Perhaps they have a more fundamental relationship to the eruptive process. Most of Hawaii's large $\left(M_{L} \geqslant 6\right)$ earthquakes are away from the volcanic centers, usually shallow, and frequently involve the flank areas or fault zones. In general, these involve readjustment of large crustal blocks to stresses caused by the growing load of the volcano or by the influx or outflux of magma at the large crustal reservoirs [Eaton and Murata, 1960]. These earthquake can be said to have a secondary relationship to eruptive activity, in that they are events caused by tectonic stresses. The large study events near the flanks of the volcanoes associated with the fault zones are consistent with this model.

Deep seismicity on Hawaii occurs mainly beneath Kilauea and Mauna Loa. Kilauea, in particular, is wellknown for intense deep swarms which are frequently related to tilt changes and/or impending eruption. Magnitudes are usually $\leqslant 3$. Deep activity is weaker at Mauna Loa, but seismicity between 35 and $50 \mathrm{~km}$ has been observed to increase somewhat before eruptions [Koyanagi et al., 1975; 


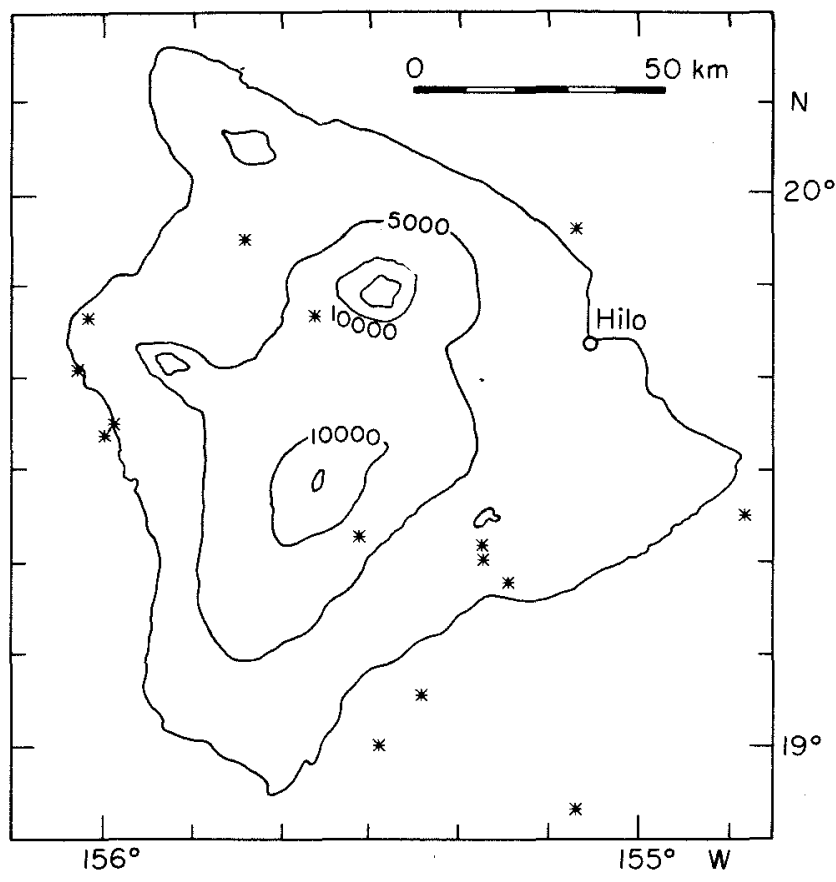

Fig. 13. All events with $M_{L} \geqslant 4.0$ and deeper than $35 \mathrm{~km}$ between 1965 and 1981. Unlike the deep swarms of smaller earthquakes, many events are away from the active volcanoes.

Decker et al., 1983]. The cause of the deep activity under the volcanoes is thought to be the entry of magma into the conduit system of the volcano. Intense shallow swarms are observed before and during eruptions at both volcanoes, caused by the opening of cracks as magma breaks to the surface. Both swarm types can be said to have a primary relationship to volcanism; seismic events are directly caused by the movement of magma.

Deep earthquakes with large magnitudes are quite rare. There were only 14 events with $M_{L} \geqslant 4, h \geqslant 35 \mathrm{~km}$ from 1965 to 1981 (Figure 13). Except for the large April 1973 study event, all of these were between magnitudes 4 and 5 . Note from Figure 10 that only four of these events are spatially related to the volcanic centers. The picture that deep activity is confined to the volcanic centers and that all other seismicity is shallow and associated with fault zones is an oversimplification. Aside from swarms under the summits, subcrustal activity is relatively uniform beneath Hawaii, and its volcanic association is not well understood. The 1973 earthquake has been suggested to be due to larger-scale, regional stresses [Unger and Ward, 1979], or a renewal of volcanism under Mauna Kea [Butler, 1982].

The May 30, 1950, deep event under Mauna Loa was clearly associated with the large eruption 3 days later. Likewise, it was suggested that the deep Kilauea earthquake in April 1951 marked a new period of activity for that volcano, which had been quiet since 1934 and which subsequently erupted from its summit in June 1952 [Macdonald, 1959]. The specific cause of these earthquakes is unknown. Deep swarms preceding eruptions have been attributed to rock fracturing from magmatic pressure. Although their magnitudes are much larger than those of the swarm events, the temporal relationship of these two events to ensuing eruptive activity suggests that they too may signify the motion of magma.

Figure 14 shows a histogram of eruptions with volumes of lava $10^{6} \mathrm{~m}^{3}$ since 1934 . Large earthquakes are indicated by a circle. Macdonald [1959] regarded the two events near Kalapana in March 1954 as precursors to the eruption in

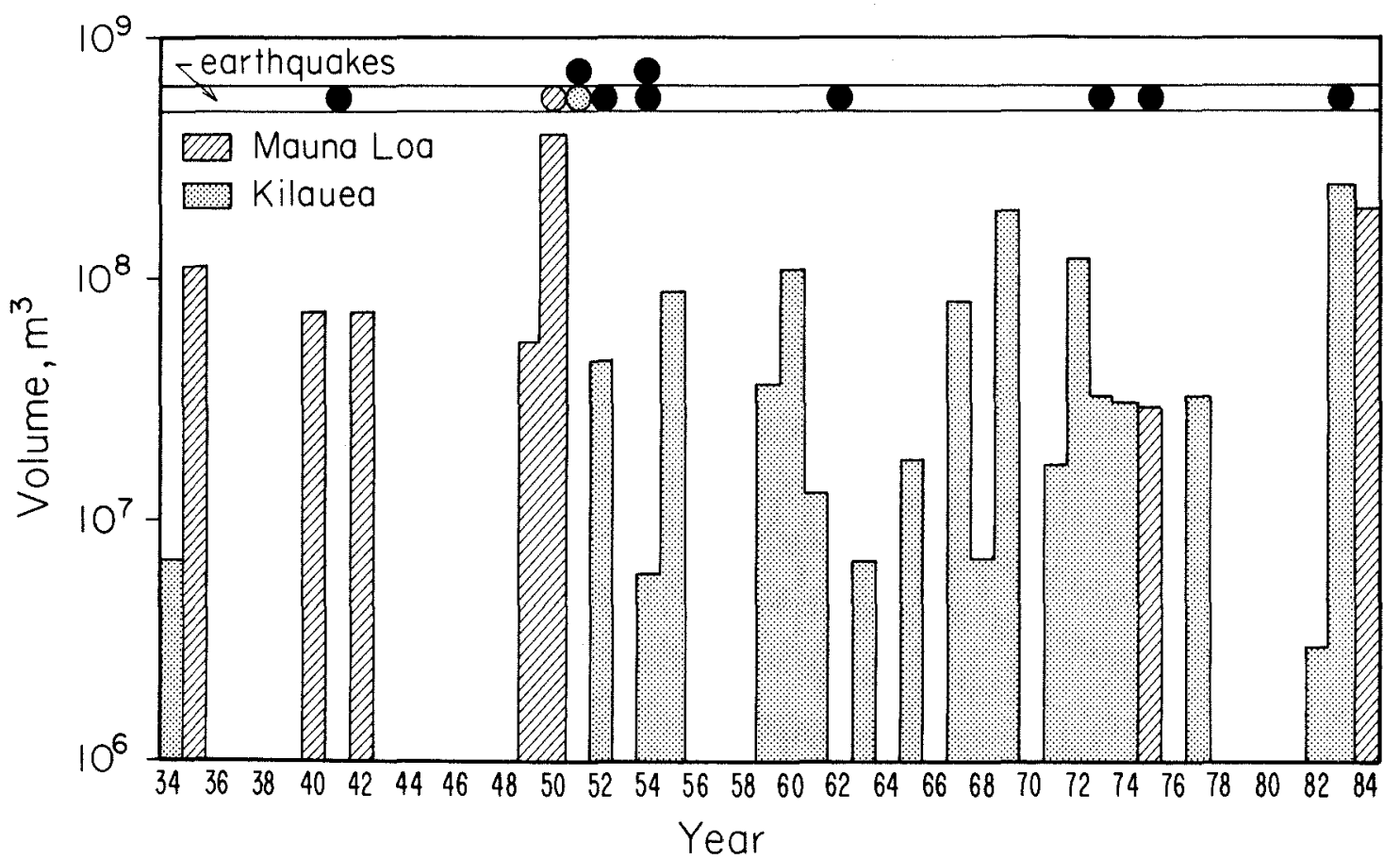

Fig. 14. Histogram of eruptions with lava volumes over $10^{6} \mathrm{~m}^{3}$ of Mauna Loa (stipled) and Kilauea (hachured) since 1934. The entire volume is plotted in the year the eruption began. Earthquakes discussed in this study are plotted above as solid circles; the shaded circles indicate the events underneath the volcanic summits. (Eruption volumes are from Macdonald et al. [1983] except for the two most recent eruptions of Kilauea and Mauna Loa (from R. Y. Koyanagi, personal communication, 1984).) 
early 1955, when Kilauea's east rift zone was active along most of its length. Our depth estimates for these events were shallow $(20-25 \mathrm{~km}$ and $\approx 10 \mathrm{~km})$. The 1975 Kalapana earthquake, in the same general area, may have been triggered by a sudden increase in the volume of magma stored in Kilauea's east rift zone [Furumoto and Kovach, 1979]. Kilauea had become active in 1952, after a quiet period of 16 years. There were subsequent eruptions in May 1954 and February 1955. Thus it is possible that the March 1954 events were related to a sudden magma increase in the east rift zone reservoir, analogous to the case of the 1975 earthquake. Correlation between other study events and eruptive activity is less obvious. Aside from the cluster of both large earthquakes and eruptions from 1949 to 1955 , there is no clear association.

\section{Conclusions}

Depths estimated for 12 moderate to large Hawaiian earthquakes from the relative excitation of body and surface waves are reasonably consistent with well-determined depths from local data. Further, the results agree with known Hawaiian seismicity patterns. The technique is useful for events before 1960, when instrumental depths were determined only rarely. The results are limited in that we used records from one station only; we attempted to correct for this by doing a general calculation of excitation for the three basic faults and taking the average of the azimuthal radiation pattern. Independent checks with global data were done to determine (1) the reliability of using one station as representative of the surface wave amplitude, and (2) the mechanism dependence of body wave amplitudes. Results suggest that depth estimates made from $A_{b}$ and $A_{s}$ observations at one station have an average accuracy of about 10 $\mathrm{km}$. This is roughly equal to the range of the azimuthally averaged, basic fault calculation. Use of whole spectra would yield more precise results than a single amplitude at one period, but a more complete treatment was not justified due to the lack of data for pre-1960 events.

In general, depth estimates of earthquakes associated with the volcanic flanks or fault and rift zones are shallow $(<20 \mathrm{~km})$. Exceptions to this are the 1941 and 1952 events. Two earthquakes under the volcanic summits, and close in time to eruptions, show large depths, rare for earthquakes of their magnitude. These were the May 1950 event under Mauna Loa and the April 1951 event under Kilauea, estimated to have depths between 40 and $55 \mathrm{~km}$ and 35 and $50 \mathrm{~km}$, respectively. Although the mechanism of these earthquakes is not known, it is possible that they have a more direct relation to magma motion, or increased magmatic pressure, than the large, shallow earthquakes associated with Hawaii's fault and rift zones.

Acknowledgments. We would like to thank Jim Westphal of the California Institute of Technology for first calling our attention to the 1950 Mauna Loa earthquake. We thank Elliot Endo of the Cascades Volcano Observatory and Robert Koyanagi of the Hawaiian Volcano Observatory for discussion of Hawaiian seismicity and preliminary information on the 1983 Kaoiki earthquake and 1984 eruption of Mauna Loa. One of us (H.K.E.) is grateful to R. P. Sharp and the donors to Caltech's 1985 Project Pahoehoe for the opportunity to see the geology of Hawaii firsthand. This research was supported by the Earth Sciences Section, National Science Foundation, grant EAR-8313223. Contribution 4149, Division of Geological and Planetary Sciences, California Institute of Technology, Pasadena, California.

\section{REFERENCES}

Ando, M., The Hawaii earthquake of November 29, 1975: Low dip angle faulting due to forceful injection of magma, J. Geophys. Res., 84, 7616-7626, 1979.

Ben-Menahem, A., M. Rosenman, and D. G. Harkrider, Fast evaluation of source parameters from isolated surface wave signals, I, Universal tables, Bull. Seismol. Soc. Am., 60, 1337-1388, 1970.

Bolt, B. A., and J. Dorman, Phase and group velocities of Rayleigh waves in a spherical, gravitating earth, $J$. Geophys. Res., 66, 2965-2981, 1961.

Brune, J. N., Tectonic stress and the spectra of seismic shear waves from earthquakes, J. Geophys. Res., 75, 4997-5009, 1970.

Butler, R., The 1973 Hawaii earthquake: A double earthquake beneath the volcano Mauna Kea, Geophys. J. R. Astron. Soc., 69, $173-186,1982$

Chen, W., and P. Molnar, Focal depths of intracontinental and intraplate earthquakes and their implications for the thermal and mechanical properties of the lithosphere, J. Geophys. Res., 88, 4183-4214, 1983.

Crosson, R. S., and E. T. Endo, Focal mechanisms of earthquakes related to the 29 November 1975 Kalapana, Hawaii earthquake: The effect of structural models, Bull. Seismol. Soc. Am., 71, 713$729,1981$.

Crosson, R. S., and R. Y. Koyanagi, Seismic velocity structure below the island of Hawaii from local earthquake data, J. Geophys. Res., 84, 2331-2341, 1979.

Decker, R. W., and R. Koyanagi, Hawaiian earthquake of November 16, 1983, Earthquake Inf. Bull., 16, 4-9, 1984.

Decker, R. W., R. Y. Koyanagi, J. J. Dvorak, J. P. Lockwood, A. T. Okamura, K. M. Yamashita, and W. R. Tanigawa, Seismicity and surface deformation of Mauna Loa volcano, Hawaii, Eos Trans. $A G U, 64,545-547,1983$.

Dziewonski, A. M., J. E. Franzen, and J. H. Woodhouse, Centroid moment tensor solutions for July-September 1984, Phys. Earth Planet. Inter., 38, 203-213, 1985.

Eaton, J. P., Crustal structure and volcanism in Hawaii, in The Crust of the Pacific Basin, Geophys. Monogr. Ser., vol. 6, edited by G. A. Macdonald and H. Kuno, pp. 13-29, AGU, Washington, D. C., 1962.

Eaton, J. P., and K. J. Murata, How volcanoes grow, Science, 132, 925-938, 1960.

Eissler, H. K., and H. Kanamori, A single-force source model for the 1975 Kalapana, Hawaii earthquake (abstract), Eos Trans. $A G U, 66,307,1985$.

Furumoto, A. S., and R. L. Kovach, The Kalapana earthquake of November 29, 1975: An intra-plate earthquake and its relation to geothermal processes, Phys. Earth Planet. Inter., 18, 197-208, 1979.

Geller, R. J., and H. Kanamori, Magnitudes of great shallow earthquakes from 1904 to 1952, Bull. Seismol. Soc. Am., 67, 587-598, 1977.

Goodstein, J. R., H. Kanamori, and W. H. K. Lee, Seismicity microfiche publications from the Caltech Archives (announcements), Bull. Seismol. Soc. Am., 70, 657-658, 1980.

Gutenberg, B., and C. F. Richter, Seismicity of the Earth and Associated Phenomena, Princeton University Press, Princeton, N. J., 1954.

Hill, D. P., Crustal structure of the island of Hawaii from seismicrefraction measurements, Bull. Seismol. Soc. Am., 59, 101-130, 1969.

Kanamori, H., The energy release in great earthquakes, $J$. Geophys. Res., 82, 2981-2987, 1977.

Kanamori, H., and G. S. Stewart, Mode of strain release along the Gibbs fracture zone, mid-Atlantic ridge, Phys. Earth Planet. Inter., 11, 312-332, 1976.

Klein, F. W., and R. Y. Koyanagi, Hawaiian Volcano Observatory seismic network history 1950-79, U.S. Geol. Surv. Open File Rep., 80-302, 1980.

Koyanagi, R. Y., H. L. Kivroy, and A. T. Okamura, The 1962 Kaoiki, Hawaii earthquake and its aftershocks, Bull. Seismol. Soc. Am., 56, 1317-1335, 1966. 
Koyanagi, R. Y., D. A. Swanson, and E. T. Endo, Distribution of earthquakes related to mobility of the south flank of Kilauea volcano, Hawaii, U.S. Geol. Surv. Prof. Pap., 800-D, D89-D97, 1972.

Koyanagi, R. Y., E. T. Endo, and J. S. Ebisu, Reawakening of Mauna Loa volcano, Hawaii: A preliminary evaluation of seismic evidence, Geophys. Res. Lett., 2, 405-408, 1975.

Lipman, P. W., Rates of volcanic activity along the southwest rift zone of Mauna Loa volcano, Hawaii, Bull. Volcanol., 43, 703725,1980

Macdonald, G. A., Activity of Hawaiian volcanoes during the years 1940-1950, Bull. Volcanol., 15, 119-179, 1954.

Macdonald, G. A., The activity of Hawaiian volcanoes during the years 1951-1956, Bull. Volcanol., 22, 3-70, 1959.

Macdonald, G. A., and C. K. Wentworth, The Kona earthquake of August 21, 1951, Volcano Lett., 513, 1-4, 1951.

Macdonald, G. A., A. T. Abbot, and F. L. Peterson, Volcanoes in the Sea, 2nd ed., 517 pp., University of Hawaii Press, Honolulu, 1983.

Nakamura, K., Why do long rift zones develop in Hawaiian volcanoes (in Japanese), Kazan, 25, 255-269, 1980.

Richter, C. F., Elementary Seismology, W. H. Freeman, San Francisco, Calif., 1958.

Stearns, H. T., Geology of the State of Hawaii, Pacific Books, Palo Alto, Calif., 1966.

Swanson, D. A., W. A. Duffield, and R. S. Fiske, Displacement of the south flank of Kilauea volcano: The result of forceful intrusion of magma into the rift zones, U.S. Geol. Surv. Prof. Pap., 963,39 pp., 1976.

Tanigawa, W. R., J. S. Nakata, and A. H. Tomori, Hawaiian Volcano Observatory summary 82 - Seismic data, January to December 1982, U.S. Geol. Surv., 1983.
Tilling, R. I., R. Y. Koyanagi, P. W. Lipman, J. P. Lockwood, J. G. Moore, and D. A. Swanson, Earthquake and related catastrophic events, Island of Hawaii, November 29, 1975: A preliminary report, U.S. Geol. Surv. Circ., 740, 33 pp., 1976.

Tréhu, A. M., J. L. Nábèlek, and S. C. Solomon, Source characterization of two Reykjanes Ridge earthquakes: Surface waves and moment tensors; $P$ waveforms and nonorthogonal nodal planes, J. Geophys. Res., 86, 1701-1724, 1981.

Unger, J. D., and P. L. Ward, A large deep Hawaiian earthquake - the Honomu, Hawaii event of April 26, 1973, Bull. Seismol. Soc. Am., 69, 1771-1781, 1979.

U.S. Geological Survey, The Volcano Letters, 1-530, 1925-1955.

Vanek, J., A. Zatopek, V. Karnik, N. V. Kondorskaya, Y. V. Riznichenko, E. F. Savarensky, S. L. Solov'ev, and N. V. Shebalin, Standardization of magnitude scales, Acad. Sci. USSR Geophys. Ser. 2, Engl. Transl., 108-111, 1962.

Ward, P. L., and S. Gregersen, Comparison of earthquake locations determined with data from a small network of stations and small tripartite arrays on Kilauea volcano, Hawaii, Bull. Seismol. Soc. Am., 63, 679-711, 1973

Wiens, D. A., and S. Stein, Age dependence of oceanic intraplate seismicity and implications for lithospheric evolution, J. Geophys. Res., 88, 6455-6468, 1983.

H. K. Eissler and H. Kanamori, Seismological Laboratory 252-21, California Institute of Technology, Pasadena, CA 91125.

(Received October 16, 1984; revised June 28, 1985; accepted August 23, 1985.) 